\title{
THE APPLICATION OF KALMAN FILTERING TO PREDICT VERTICAL RAIL AXIS DISPLACEMENTS OF THE OVERHEAD CRANE BEING A COMPONENT OF SEAPORT TRANSPORT STRUCTURE
}

\author{
Daria FILIPIAK - KOWSZYK ${ }^{1}$, \\ Waldemar KAMIŃSKI ${ }^{1,2}$, \\ 1) Gdansk University of Technology, Poland \\ 2) University of Warmia and Mazury in Olsztyn, Poland
}

\begin{abstract}
As the devices designed to transport materials, the overhead cranes should meet certain geometric requirements for their operation to be safe. The presently available geodetic equipment, in particular total stations, provides opportunities for precise 3D measurements of coordinates of the controlled points. These coordinates make a basis for correcting the height of crane runway axes. The paper presents a method to calculate position corrections for the crane rail axes in both vertical and horizontal direction, and indicates that these results can find much wider application. Among other goals, the observations of this type, along with the Kalman filtration method, can be used to predict vertical displacements of the crane rail axes. The object of practical considerations in the paper is a crane working in the area with unfavourable geotechnical conditions and the settling limits attributed to this crane and location area in the technical design. The sample practical application has confirmed the validity of the use of the proposed solution for evaluating the operational safety of the crane. Although the tests were performed for the gantry crane, the proposed solution is believed to be applicable for other types of overhead cranes.
\end{abstract}

Keywords: operational safety of the crane, rectification corrections, parametric method with conditions imposed on parameters, prediction, Kalman filtering

\section{INTRODUCTION}

Kalman filtering [10] is frequently used in numerical calculations performed in various fields of technology, including land, inland and sea navigation, and geodesy. The use of Kalman filtering for monitoring deformations of engineering objects, such as water dams for instance, is discussed in [9]. The application of the Kalman filter in marine navigation allows the operator, among other aspects, to make decisions which help the watercraft unit to reach safely the target $[2,4,5,16,18$, etc.]. The paper which is also worth noticing here is Ref. [15], in which the author describes the ship position estimation procedure making use of the extended Kalman filter with robust adjustment. Besides, Kalman filtering can be applied to track objects, which is discussed in Ref. [17], among other sources. Along with marine applications, Kalman filtering can be used in numerical analyses of the operation of devices composing port infrastructure. A device of this type which is used in maritime industry to transport materials is the overhead crane. The cranes are very frequently installed on quays, in ports, shipyards, etc. They transport materials in both vertical and horizontal directions. They operate simultaneously with other devices used in maritime industry (for instance: hoists, fork-lift trucks, road transport, etc.), and also with continuingly moving human teams at work. Those and other aspects are reasons why constant monitoring of runways and rectification of crane rail axes are of utmost importance for ensuring the safety of crane's operation and transport. One of tasks of engineering geodesy is measurement of crane rail axes. Numerous publications have been devoted to the operation of overhead cranes. Some of them, $[1,7,8,12,14]$ for instance, discuss issues related with the methodology of measurement and control of crane rail axes, while other authors focus their attention on geometric conditions which should be met for the overhead crane to operate faultlessly, [13] for instance. Standard measurements used for this purpose have the form of observations done by integrated total stations. The presently available total stations enable to perform measurements at very high accuracy, which leads to high accuracy of the final estimation of, for instance, point coordinates. Technical reference manuals and standards provide permissible deviations for crane runways, which are used as the limits for correct operation of the overhead 
crane. The cranes can be installed in different parts of the quay, even those with very unfavourable geotechnical conditions. Locations of this type can cause displacements of the ground on which the crane rails are laid. This problem refers to field cranes operating on the ground. It can also lead to the displacement of track bed pillars and crane beams. In contrast, it does not refer to suspended travelling cranes or gantry cranes working in closed rooms or at certain heights. The presented situations can disturb the initial, correct geometry of the crane rail axes and, consequently, lead to construction disaster. Horizontal and vertical displacements of the crane pose a threat for people and port infrastructure equipment situated in its vicinity. The measurements intended to estimate these displacements make use of, as a reference, a number of controlled points situated on the ground or on track bed pillars.

In the paper, the authors propose a method which makes use of the observations basically oriented on controlling the crane runway axes to predict and estimate the value of vertical displacements of the crane. The controlled points used for this purpose should be situated on the rail segment fixed to the crane beam lying on the track bed pillar. The estimation method used to solve this task is the Kalman filtering method.

The practical sample cases presented in the paper were analysed using simulated results of measurements. They enabled to verify the assumptions adopted in the theoretical part of the work.

Although the theoretical considerations, the simulated results, and the real case analyses making use of these results refer to only one type of crane, which is the gentry crane, the proposed method can also be used for other types of overhead cranes.

\section{CALCULATING RECTIFICATION CORRECTIONS IN 3D SYSTEM}

Calculating rectification corrections plays an important role in correct operation of the overhead crane and, consequently, in the safety of its operation in the vicinity of port infrastructure objects. The calculated correction values enable to rectify the crane rail axes in such a way that the rails meet certain geometric requirements, and that the operation of the crane is not only correct but also most effective. The crane rail axis measurement is possible due to the use of total stations, among other aspects. The observations performed using the polar method and the principles of trigonometric rectification enable to obtain $3 \mathrm{D}$ coordinates in the local reference system fixed to the object. An essential stage of the measurement is position estimation of the controlled points situated on the crane rail axes. Tools which are helpful in this task include: the rule, millimetre graduation, scissors type centring tool, and clamp with central point [7]. Figure 1 shows a sample device of this type.

The above quoted literature describes standard principles of measurement and processing of the results of observations performed in order to calculate rectification corrections for crane rail axes. In this paper the authors use the original method described in $[6,11]$ to solve the problem in the local $3 \mathrm{D}$ reference system. The estimation method used to calculate the rectification corrections for crane rail axes is the parametric method with conditions imposed on parameters (for instance $[3,19,20])$. The quoted references analyse in detail the issue of calculating corrections for crane rail axes in $3 \mathrm{D}$, and include simulated real cases referring to different types of overhead cranes. Since calculating corrections is not the main subject of this paper, only basic assumptions of this method are presented here.

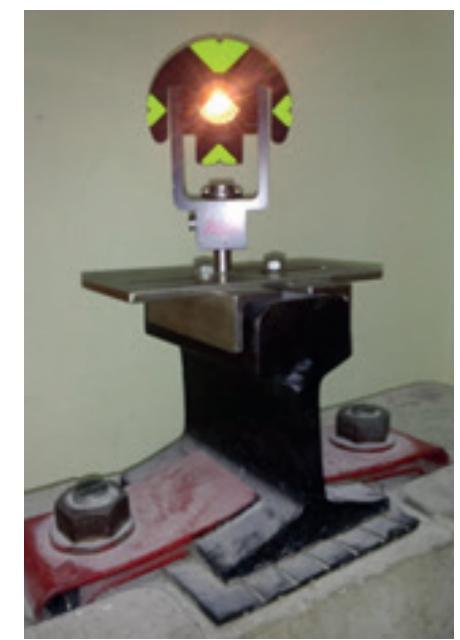

Fig. 1. Clamp with central point and mini prism Source: photo from own collection

Let us adopt the following system of observation equations for particular crane rails:

$$
\begin{gathered}
\text { left rail } y=a x+b \\
\text { right rail } y=a z+b+c
\end{gathered}
$$

and the corresponding system of correction equations in the form:

$$
\begin{array}{ll}
\text { left rail } & v_{y_{j L}}=a x_{j}+b-y_{j} \\
\text { right rail } & v_{y_{j P}}=a x_{j}+b+c-y_{j}
\end{array}
$$

The observation equation for the height of both rails can have the form of the relation

$$
\mathrm{z}=\mathrm{z}^{\mathrm{w}}
$$

with the correction equation

$$
v_{\mathrm{zj}}=\mathrm{z}^{\mathrm{w}}-\mathrm{z}_{\mathrm{j}}
$$

In relations (1), (2), (3), (4) the following nomenclature is used:

$v_{y j L}, v_{y j \mathrm{P}} v_{\mathrm{zj}}$ - corrections for $\mathrm{y}$ and $\mathrm{z}$ coordinates, respectively $\mathrm{a}, \mathrm{b}, \mathrm{c}, \mathrm{z}^{\mathrm{w}}$ - estimated parameters

$\mathrm{x}_{\mathrm{j}}, \mathrm{y}_{\mathrm{i}}, \mathrm{z}_{\mathrm{j}}$ - coordinates of controlled points

$j=1,2, \ldots, n$, where $n-$ number of controlled points.

According to the assumptions of the parametric method with conditions imposed on parameters, the problem of calculating rectification corrections for crane rail axes can be given in the form of the following equation system:

$$
\left.\begin{array}{l}
A X+L=v \\
B X+\Omega=0
\end{array}\right\}
$$


where:

$\mathrm{A}, \mathrm{B}$ - matrices of known coefficients

$\mathrm{X}$ - vector of unknowns (model parameters)

$\mathrm{L}$ - vector of measurement results or free terms

$v$ - vector of rectification corrections of crane rail axes

$\Omega$ - vector of free terms resulting from geometric conditions of the overhead crane.

The model parameters $\mathrm{X}$ and the rectification corrections $\mathrm{v}$ can be determined using a simplified approach to the problem (5), discussed for instance in Ref. [19]. We assume that the condition equation $(\mathrm{BX}+\Omega=0)$ is an additional correction equation with very large weight values, after which we can solve the problem in a way typical for parametric methods. We can write

$$
\tilde{A} X+\tilde{L}=\tilde{v}
$$

where:

$$
\tilde{A}=\left[\begin{array}{l}
A \\
B
\end{array}\right], \tilde{L}=\left[\begin{array}{l}
L \\
\Omega
\end{array}\right], \tilde{v}=\left[\begin{array}{c}
v \\
v_{\Omega}
\end{array}\right]
$$

In the calculations we make use of the weight matrix $\tilde{P}=\left[\begin{array}{cc}P & 0 \\ 0 & P_{\infty}\end{array}\right]$ in which $\mathrm{P}$ is the diagonal matrix of weights related to free terms $\mathrm{L}$, while $\mathrm{P}_{\infty}$ represents the diagonal matrix of weights for the imposed geometric conditions. The latter matrix is defined in such a way that the vector of corrections $\mathrm{v}_{\Omega}$ obtained as the final solution is equal to zero $\left(\mathrm{v}_{\Omega}=0\right)$.

The model parameters $\mathrm{X}$ are determined from the following equation form:

$$
X=-\left(\tilde{A}^{T} \tilde{P} \tilde{A}\right)^{-1} \tilde{A}^{T} \tilde{P} \tilde{L}
$$

while the control corrections $\mathrm{v}$ for the crane rail axes are determined from the relation

$$
\tilde{v}=\left[\begin{array}{c}
v \\
v_{\Omega}
\end{array}\right]=-\tilde{A}\left(\tilde{A}^{T} \tilde{P} \tilde{A}\right)^{-1} \tilde{A}^{T} \tilde{P} \tilde{L}+\tilde{L}
$$

Due to limited volume of the paper, the authors do not discuss the subject matter of accuracy represented by the covariance matrices. Relevant derivations can be found in $[3,6,11,19]$.

\section{PREDIDCTION, KALMAN METHOD FILTRATION}

When solving the task with the aid of Kalman filtration, we should take into account not only parameters describing the model position, but also those characteristic for the kinematic model of the examined object. This way we can create the state vector with components representing both object position and kinematic parameters, obtained from other independent measurements. The dynamic model enables to predict the behaviour of the object after a specified time interval. As mentioned above, the basic goal of the paper is to determine vertical displacements of the overhead crane based on the results of measurements performed to correct the rail axes. Consequently, only those basic principles of Kalman filtration are presented in the paper which are essential for correct understanding of the analysed problem. In a broader range the problem of Kalman filtration and prediction is described in [20], among other references.

The essential stage related to prediction and filtration is building a dynamic model of the object. Here, the following form of the dynamic model is adopted (after [20])

$$
\left\{\begin{array}{c}
z_{i}^{w}=z_{k=0}^{w}-V_{k=0} \Delta t_{i}-\frac{1}{2} \bar{a}_{k=0} \Delta t_{i}^{2}+e_{1} \\
V_{i}=V_{k=0}+\Delta t_{i} \bar{a}_{k=0}+e_{2} \\
\bar{a}_{i}=\bar{a}_{k=0}+e_{3}
\end{array}\right.
$$

where:

$z_{i}^{w}, V_{i}, \bar{a}_{i}-$ model parameters (respectively: height, velocity, acceleration) at the prediction time $t_{i}$

$z_{k=0}^{w}, V_{k=0}, \bar{a}_{k=0}$ - model parameters at the starting time of measurements $\mathrm{t}_{\mathrm{k}=0}$ (starting time, initial measurement)

$\Delta \mathrm{t}_{\mathrm{i}}=\mathrm{t}_{\mathrm{i}}-\mathrm{t}_{\mathrm{k}=0}$ - time interval

$\mathrm{e}_{1}, \mathrm{e}_{2}, \mathrm{e}_{3}-$ random disturbances

The relation (9), which defines prediction of the state vector $\bar{X}_{i}$ at time $\mathrm{t}_{\mathrm{i}}$, can be written in the following matrix form

$$
\begin{gathered}
{\left[\begin{array}{c}
Z_{i}^{w} \\
V_{i} \\
\bar{a}_{i}
\end{array}\right]=\left[\begin{array}{ccc}
1 & -\Delta t_{i} & -\frac{1}{2} \Delta t_{i}^{2} \\
0 & 1 & \Delta t_{i} \\
0 & 0 & 1
\end{array}\right]\left[\begin{array}{l}
Z_{k=0}^{w} \\
V_{k=0} \\
\bar{a}_{k=0}
\end{array}\right]+\left[\begin{array}{l}
e_{1} \\
e_{2} \\
e_{3}
\end{array}\right]} \\
\bar{X}_{i}=\phi_{\mathrm{kli}} \bar{X}_{k=0}+e_{i}
\end{gathered}
$$

where:

$\bar{X}_{k=0}-$ state vector at time $\mathrm{tk}=0$

$\phi_{\mathrm{k} \mid \mathrm{i}}$ - transition matrix between states $\bar{X}_{i}$ and $\bar{X}_{k=0}$

$\mathrm{e}_{\mathrm{i}}-$ vector of random disturbances

The prediction can be determined for an arbitrary time $t_{i}$, including the time period $t_{k+1}$ of new geodetic measurements. An important role in making predictions is played by the transition matrix $\phi_{\mathrm{k} \mid \mathrm{i}}$. For the calculated prediction the covariance matrix $C_{\bar{X}_{i}}$ has the form [20]:

$$
C_{\bar{X}_{i}}=\phi_{\mathrm{k} \mid \mathrm{i}} C_{\bar{X}_{k=0}} \phi_{\mathrm{k} \mid \mathrm{i}}^{T}+C_{e_{i}}
$$

Here we can assume [20] that the covariance matrix is

$$
C_{\bar{X}_{k=0}}=C_{e_{i}}=\left[\begin{array}{lll}
m_{z_{i}^{w}}^{2} & & \\
& m_{V_{i}}^{2} & \\
& & m_{\bar{a}_{i}}^{2}
\end{array}\right]
$$

For prediction purposes we can assume [20] that $\mathrm{E}\left(\mathrm{e}_{\mathrm{i}}\right)=0$, ( $\mathrm{E}$ - the expected value operator), hence

$$
\bar{X}_{i}=\phi_{\mathrm{k} \mid \mathrm{i}} \bar{X}_{k=0}
$$

As mentioned above, in filtration problems, along with geodetic observations made in the time period $t_{k=0}$ we should know the velocity or acceleration, or both of them, obtained from another independent measurement of the examined object. Kalman filtration enables to take into account 
prediction when balancing new observations $l_{k+1}$ made in the time period $t_{k+1}$ (current measurement). The Kalman filtration algorithm which takes into account both prediction and new results of measurement can be presented in the following way:

1. Building the system of observation equations in the form

$$
v_{k+1}=A_{k+1} v_{\bar{X}, k+1}+L_{k+1}
$$

where:

$\mathrm{v}_{\mathrm{k}+1}$ - vector of corrections for observation $l_{k+1}$ made in time period $t_{k+1}$

$A_{k+1}$ - matrix of known coefficients at time $t_{k+1}$

$\mathrm{V}_{\overline{\mathrm{X}}, \mathrm{k}+1}-$ vector of corrections for prediction in time period $\mathrm{t}_{\mathrm{k}+1}$

$\mathrm{L}_{\mathrm{k}+1}-$ vector of free terms at time $\mathrm{t}_{\mathrm{k}+1}$

2. Building the matrix of weights of the correction prediction vector $\mathrm{P}_{\mathrm{v}, \mathrm{k}+1}$.

$$
P_{v, k+1}=\left(P_{k+1}^{-1}+A_{k+1} P_{\bar{X}_{k+1}^{-1}}^{-1} A_{k+1}^{T}\right)^{-1}
$$

where:

$\mathrm{P}_{\mathrm{k}+1}$ - matrix of weights (given for results of observation, velocity, and acceleration)

$P_{\bar{X}_{k+1}}$ - matrix of weights of the state vector $\left(P_{\bar{X}_{k+1}}=C_{\bar{X}_{i=k+1}}^{-1}\right)$

3. Determining the gain matrices

- gain matrix for corrections: $K_{k+1}=P_{k+1}^{-1} P_{v, k+1}$,

- gain matrix for parameters: $K_{X, k+1}=-P_{\bar{X}_{k+1}}^{-1} A_{k+1}^{T} P_{v, k+1}$.

4. Calculating corrections for observation $\mathrm{v}_{\mathrm{k}+1}$ and corrections $\mathrm{v}_{\overline{\mathrm{X}}, \mathrm{k}+1}$ for prediction (relations (19) and (20), respectively)

$$
\begin{gathered}
v_{k+1}=K_{k+1} L_{k+1} \\
v_{\bar{X}, k+1}=K_{X, k+1} L_{k+1}
\end{gathered}
$$

5. Calculating the vector of balanced observations $\widehat{L}_{k+1}$ (21), the state vector $\hat{X}_{k+1}(22)$, and the variance coefficient estimator $\hat{\sigma}_{0}^{2}(23)$

$$
\begin{gathered}
\hat{L}_{k+1}=l_{k+1}+v_{k+1} \\
\hat{X}_{k+1}=\bar{X}_{k+1}+v_{\bar{X}, k+1} \\
\hat{\sigma}_{0}^{2}=m_{0}^{2}=\frac{1}{n_{k+1}}\left(v_{k+1}^{T} P_{k+1} v_{k+1}+v_{\bar{X}, k+1}^{T} P_{\bar{X}, k+1} v_{\bar{X}, k+1}\right) \\
\left(\mathrm{n}_{\mathrm{k}+1}-\text { number of observations made at time } \mathrm{t}_{\mathrm{k}+1}\right) .
\end{gathered}
$$

The use of prediction and Kalman filtration enables to predict the scale of settlement of the controlled points in the time interval between successive measurements, and to balance the geodetic observation with the aid of prediction. The above procedure can be used to control the crane runway axes, as well as to calculate vertical displacements, indispensable when assessing the operational safety of the overhead crane. It was assumed in the paper that the crane runway settles due to its unfavourable location, on an unstable quay ground for instance. What is also of high importance is calculating the maximal permissible limit for vertical displacement which will not lead to construction disaster. This task is to be agreed with the designer or construction expert.

\section{SAMPLE PRACTICAL APPLICATION}

The measurements done by the total station provide $\mathrm{x}, \mathrm{y}, \mathrm{z}$ coordinates of the controlled points. The presented sample of practical application bases on simulated data. For this purpose the positions of 8 controlled points uniformly distributed along crane rail axes were assumed, see Fig. 2. Moreover, for the purpose of the present analysis an assumption was adopted that settling of the system by up to $30 \mathrm{~mm}$ does not threat with construction disaster.

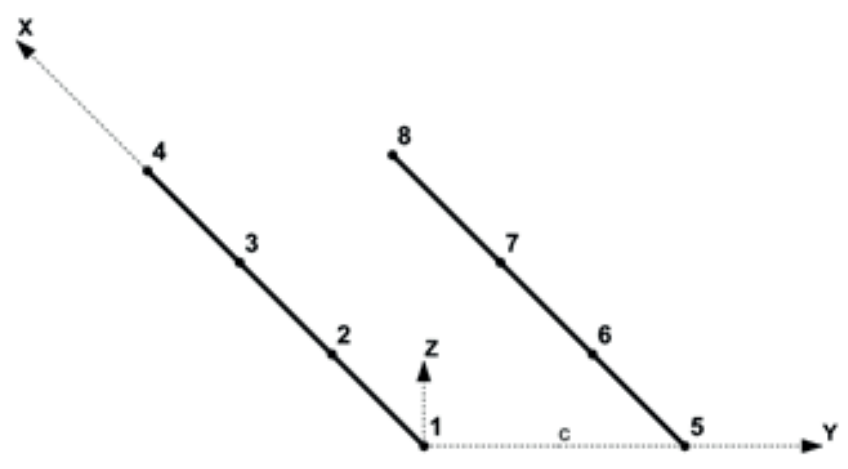

Fig. 2. Distribution of controlled points

In the local 3D reference system the controlled points 1-4 are situated on the left rail axis of the overhead crane, while those numbered 5-8 on the right rail axis. The calculations were performed for a gantry crane. The rails are assumed parallel to each other and distant by $\mathrm{c}=8 \mathrm{~m}$. Table 1 collates the coordinates simulated for the time $t_{k=0}$. Moreover, the correction equations based on relations (2) and (4) were built.

Tab. 1. Simulated coordinates of controlled points

\begin{tabular}{|c|c|c|c|}
\hline No of point & $\mathrm{x}[\mathrm{mm}]$ & $\mathrm{y}[\mathrm{mm}]$ & $\mathrm{z}[\mathrm{mm}]$ \\
\hline 1 & 0 & 0 & 0 \\
\hline 2 & 4004 & 10 & -10 \\
\hline 3 & 7996 & 8 & -15 \\
\hline 4 & 11992 & -6 & -10 \\
\hline 5 & 16 & 8012 & -5 \\
\hline 6 & 3998 & 7998 & -15 \\
\hline 7 & 8010 & 8006 & -20 \\
\hline 8 & 11998 & 8002 & -10 \\
\hline
\end{tabular}

The assumed distance between the rail axes, $\mathrm{c}=8000 \mathrm{~mm}$, enabled to formulate the condition equation in the form $c-8000=0$ 
The relations (7) and (8) were used to calculate parameters and corrections needed to adjust the crane rail axes. The results obtained in the time period $\mathrm{t}_{\mathrm{k}=0}$ are 4 given in Table 2 . The calculations were performed assuming unit weights for free terms L and the weight $p=20000$ for the assumed geometric condition.

Tab. 2. Results calculated at time $t_{k=0}$

\begin{tabular}{|c|c|c|}
\hline \multicolumn{2}{|c|}{ Parameters and corrections } & {$[\mathrm{mm}]$} \\
\hline \multirow{4}{*}{ 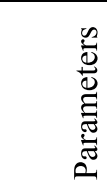 } & $a$ & 0 \\
\hline & $b$ & 7 \\
\hline & $C$ & 8000 \\
\hline & $Z$ & -11 \\
\hline \multirow{17}{*}{$\begin{array}{l}0 \\
.0 \\
.0 \\
0 \\
0 \\
0\end{array}$} & $v_{1}$ & 7 \\
\hline & $v_{1}$ & -11 \\
\hline & $v_{2}$ & -5 \\
\hline & $v_{2}$ & -1 \\
\hline & $v_{3}$ & -5 \\
\hline & $v_{3}$ & 4 \\
\hline & $v_{4}$ & 7 \\
\hline & $v_{4}$ & -1 \\
\hline & $v_{5}$ & -5 \\
\hline & $v_{5}$ & -6 \\
\hline & $v_{6}$ & 7 \\
\hline & $v_{6}$ & 4 \\
\hline & $v_{7}$ & -3 \\
\hline & $v_{7}$ & 9 \\
\hline & $v_{8}$ & -1 \\
\hline & $v_{8}$ & -1 \\
\hline & $v$ & 0 \\
\hline
\end{tabular}

The calculated results shown in Table 2 make the basis for possible adjustments of crane rail axes in the time period $t_{k=0}$, according to the applicable tolerances.

The results of observations of dynamic parameters, simulated from an independent measurement, are the following:

- settling rate of the points $\mathrm{V}_{\mathrm{k}=0}=0,01 \mathrm{~m} /$ year, with the mean error $\mathrm{m}_{\mathrm{v}}=0,002 \mathrm{~m} /$ yēar

- constant acceleration $\mathrm{a}_{\mathrm{k}=0}=0,005 \mathrm{~m} /$ year $^{2}$, with mean error $\mathrm{m}_{\mathrm{a}}=0,001 \mathrm{~m} /$ year $^{2}$.

The height values obtained in the time period $t_{k=0}$ and the simulated kinetic parameters were used to calculate the displacement prediction at times $i=1 / 2$ year and $i=1$ year.

$\underline{\text { State vector prediction for time } \mathrm{i}=1 / 2 \text { year }}$

Here, the transition matrix has the form

$$
\phi_{\mathrm{k} \mid \mathrm{i}}=\left[\begin{array}{ccc}
1 & -0,5 & -0,125 \\
0 & 1 & 0,5 \\
0 & 0 & 1
\end{array}\right]
$$

The state vector $\overline{\mathrm{X}}_{\mathrm{k}=0}$ can be presented in the form

$$
\bar{X}_{k=0}=\left[\begin{array}{c}
z_{k=0}^{w}=-11 \\
V_{k=0}=10 \\
\bar{a}_{k=0}=5
\end{array}\right]\left[\begin{array}{c}
m m \\
\text { mm/1year } \\
m m / 1 \text { year }
\end{array}\right]
$$

Hence, based on relation (14) the state vector $\overline{\mathrm{X}}_{\mathrm{i}=1 / 2}$ takes the form

$$
\bar{X}_{i=1 / 2}=\left[\begin{array}{l}
z_{i=1 / 2}^{w} \\
V_{i=1 / 2} \\
\bar{a}_{i=1 / 2}
\end{array}\right]=\left[\begin{array}{c}
-16,6 \\
12,5 \\
5,0
\end{array}\right]\left[\begin{array}{c}
m m \\
\text { mm/1year } \\
\text { mm/1year } 2
\end{array}\right]
$$

A conclusion which can be derived from the performed calculations is that after half a year the observed system will settle by $5,6 \mathrm{~mm}$, reaching the level $z_{i=1 / 2}^{w}=-16,6 \mathrm{~mm}$. This value does not exceed the limit of $30 \mathrm{~mm}$ assumed before the beginning of observation.

The relation (12) was used to calculate mean errors of the prediction, shown in Table 3.

Tab.3. Mean prediction errors

\begin{tabular}{|c|c|c|c|}
\hline $\boldsymbol{m}_{\boldsymbol{i}}$ & $m_{z_{i=1 / 2}^{w}}$ & $m_{V_{i=1 / 2}}$ & $m_{\bar{a}_{i=1 / 2}}$ \\
\hline$[\mathbf{m m}]$ & 1,4 & 0,9 & 1,4 \\
\hline
\end{tabular}

\section{$\underline{\text { State vector prediction for time } i=1 \text { year }}$}

The transition matrix has the following form

$$
\phi_{\mathrm{k} \mid \mathrm{i}}=\left[\begin{array}{ccc}
1 & -1 & -0,5 \\
0 & 1 & 1 \\
0 & 0 & 1
\end{array}\right]
$$

After determining the state vector $\overline{\mathrm{X}}_{\mathrm{i}=\text { lyear }}$ we get

$$
\bar{X}_{i=1 \text { year }}=\left[\begin{array}{l}
Z_{i=1 \text { year }}^{w} \\
V_{i=1 \text { year }} \\
\bar{a}_{i=1 \text { year }}
\end{array}\right]=\left[\begin{array}{c}
-23,5 \\
15,0 \\
5,0
\end{array}\right]\left[\begin{array}{c}
\mathrm{mm} \\
\text { mm/1year } \\
\text { mm/1year }
\end{array}\right]
$$

The performed analysis shows that the object will keep settling until it reaches the level of $z_{i=1}^{w}$ year $=-23,5 \mathrm{~mm}$, but it still will not exceed the assumed permissible limit of 30 $\mathrm{mm}$. Table 4 shows mean errors $\overline{\mathrm{X}}_{\mathrm{i}=1 \mathrm{year}}$ of the state vector.

Tab.4. Mean errors of prediction

\begin{tabular}{|c|c|c|c|}
\hline $\boldsymbol{m}_{\boldsymbol{i}}$ & $m_{z_{i=1}^{w} \text { year }}$ & $m_{V_{i=1 \text { year }}}$ & $m_{\bar{a}_{i=1} \text { year }}$ \\
\hline$[\mathbf{m m}]$ & 1,6 & 1,2 & 1,4 \\
\hline
\end{tabular}

In the sample real application it was assumed that after one year (time period $t_{k+1}$ ) new measurements were performed, which enabled further calculations of the four following variants:

variant I: settling of the entire system by $10 \mathrm{~mm}$ after one year

variant II: settling of the entire system by $5 \mathrm{~mm}$ after one year 
variant III: settling of the left rail by $5 \mathrm{~mm}$, and the right rail by $10 \mathrm{~mm}$ after one year

variant IV: points $1,2,4,5$, and 8 settled by $10 \mathrm{~mm}$, while points $3,6,7$ by $5 \mathrm{~mm}$.

Calculations of all four variants, taking in to account the yearly prediction, were performed using the above presented Kalman filtration algorithm. The obtained results are collated in Table 5. The estimation was done assuming unit weights for free terms $\mathrm{L}_{\mathrm{k}+1}$ and the weight $\mathrm{p}=20000$ for the assumed geometric condition.

Tab. 5. Results of calculations at time $t_{k+1}$

\begin{tabular}{|c|c|c|c|c|c|}
\hline \multicolumn{2}{|c|}{ Parameters and corrections } & $\begin{array}{c}\text { Variant I } \\
{[\mathrm{mm}]}\end{array}$ & $\begin{array}{c}\text { Variant II } \\
\text { [mm] }\end{array}$ & $\begin{array}{c}\text { Variant III } \\
{[\mathrm{mm}]}\end{array}$ & $\begin{array}{c}\text { Variant IV } \\
{[\mathrm{mm}]}\end{array}$ \\
\hline \multirow{6}{*}{ 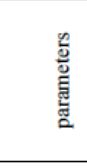 } & $a$ & 0,0 & 0,0 & 0,0 & 0,0 \\
\hline & $b$ & 6,9 & 6,9 & 6,9 & 6,9 \\
\hline & $c$ & 8000 & 8000 & 8000 & 8000 \\
\hline & $z^{w}-$ & $-24,1$ & $-29,1$ & $-26,6$ & $-26,0$ \\
\hline & $V$ & 5,0 & 5,0 & 5,0 & 5,0 \\
\hline & $\bar{a}$ & 0,0 & 0,0 & 0,0 & 0,0 \\
\hline \multirow{19}{*}{ 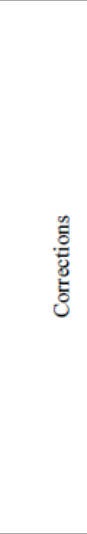 } & $v_{y 1}$ & 6,9 & 6,9 & 6,9 & 6,9 \\
\hline & $v_{z 1}$ & $-10,6$ & $-10,6$ & $-8,1$ & $-12,5$ \\
\hline & $v_{y 2}$ & $-5,2$ & $-5,2$ & $-5,2$ & $-5,2$ \\
\hline & $v_{z 2}$ & $-0,6$ & $-0,6$ & 1,9 & $-2,5$ \\
\hline & $v_{y 3}$ & $-5,3$ & $-5,3$ & $-5,3$ & $-5,3$ \\
\hline & $v_{z 3}$ & 4,4 & 4,4 & 6,9 & 7,5 \\
\hline & $v_{y 4}$ & 6,6 & 6,6 & 6,6 & 6,6 \\
\hline & $v_{z 4}$ & $-0,6$ & $-0,6$ & 1,9 & $-2,5$ \\
\hline & $v_{y 5}$ & $-5,1$ & $-5,1$ & $-5,1$ & $-5,1$ \\
\hline & $v_{z 5}$ & $-5,6$ & $-5,6$ & $-8,1$ & $-7,5$ \\
\hline & $v_{y 6}$ & 6,8 & 6,8 & 6,8 & 6,8 \\
\hline & $v_{z 6}$ & 4,4 & 4,4 & 1,9 & 7,5 \\
\hline & $v_{y 7}$ & $-3,3$ & $-3,3$ & $-3,3$ & $-3,3$ \\
\hline & $v_{z 7}$ & 9,4 & 9,4 & 6,9 & 12,5 \\
\hline & $v_{y 8}$ & $-1,4$ & $-1,4$ & $-1,4$ & $-1,4$ \\
\hline & $v_{z 8}$ & $-0,6$ & $-0,6$ & $-3,1$ & $-2,5$ \\
\hline & $v_{c}$ & 0,0 & 0,0 & 0,0 & 0,0 \\
\hline & $v_{V}$ & 0,0 & 0,0 & 0,0 & 0,0 \\
\hline & $v_{\bar{a}}$ & 0,0 & 0,0 & 0,0 & 0,0 \\
\hline
\end{tabular}

The obtained results can have the following interpretations:

1. Settling of the entire object.

The largest object settling, which neared the assumed limits, was observed for variant II $\left(\mathrm{z}^{\mathrm{w}}=-29.1 \mathrm{~mm}\right)$. However, taking into account the fact that the assumed permissible limit for both crane rail heights cannot exceed $30 \mathrm{~mm}$, we can conclude that the results obtained for all variants are correct.

2. Crane rail axis rectification corrections obtained in successive variants.

The results of these calculations provided the information about the values of the rectification corrections in both horizontal and vertical plane. They allow to conclude that the values of rectification corrections in the horizontal plane are exactly the same in all analysed variants. The higher values of the rectification corrections for the majority of the controlled points along the vertical axis of the system are observed in variant IV. However, if we assume that the rail level difference in particular cross sections cannot exceed $10 \mathrm{~mm}$ and compare corresponding zi values of the controlled points we can conclude that this deviation is not exceeded, regardless of the variant.

\section{CONCLUSIONS}

The above analysis reveals that the operational safety of the overhead crane as a port infrastructure component depends on many factors. Along with geometric conditions which the correctly working crane should meet, these factors also include its location. The method to calculate $3 \mathrm{D}$ crane axis rectification corrections which is proposed in $[6,11]$ offers the possibility to use the results for predicting object settling and calculating vertical displacements. The proposed solution can be used to analyse cases when the overhead crane is located in a place with unfavourable geotechnical conditions. The performed calculations making use of the simulated data confirm the applicability of the Kalman filtration to analysing the presented problem. Moreover, the developed dynamic model enables to predict the behaviour of the object after a certain time period. This piece of information is essential for evaluating the operational safety of the working crane, as well the safety of people and the equipment in its vicinity. Although both the theoretical analysis and the simulated data based practical calculations were performed for the gantry crane, the proposed methodology can also be applied to other types of overhead cranes. Practical application of the here presented theoretical considerations was confirmed using the simulated data. As the next step of the here reported activities, authors are going to perform analyses based on real data.

\section{BIBLIOGRAPHY}

1. Anigacz W., Modification of geodetic design methods for overhead crane runway rectification, (in Polish), Opole University of Technology, Studies and Monographs, z.57, Opole, 1992

2. Banachowicz A., Structure of Kalman Filter at an algorithm of Integrated Navigation System, Proceedings of 2nd Symposium on "Integrated Navigation", Maritime University of Szczecin, 2000.

3. Baran L. W., Theoretical principles of processing of geodetic measurement results (in Polish), Wydawnictwo Naukowe PWN, Warsaw, 1999

4. Borkowski P., Data fusion in a navigational decision support system on a sea-going vessel, Polish Maritime Research, No 4(76), Vol. 19, pp. 78-87, 2012, DOI 10.2478/ v10012-012-0043-1

5. Borkowski P., Magaj J., Mąka M, Positioning based on multi-sensor Kalman filter (in Polish), Scientific Journals of the Maritime University of Szczecin, 13,(85), pp 5-9, 2008.

6. Filipiak D., Kamiński W., Determination of rectification corrections for semi gantry crane rail axes in the local 3D coordinate system, Reports on Geodesy and Geoinformatics, vol. 97/2014, 71-79, DOI: 10.2478/rgg2014-0012, 2014 
7. Gocał J., Engineering and industrial geodesy. Part III (in Polish), Wydawnictwo AGH, Krakow, 2010

8. Grala M., \& Kopiejewski G., Engineering Geodesy. Selected divisions. (in Polish), Wyd. UWM, Olsztyn, 2003

9. Gulal E., Structural deformations analysis by means of Kalman-filtering., Boletim De Ciencias Geodesicas, Volume: 19 Issue: 1 Pages: 98-113 Published: JAN-MAR, 2013, DOI 10.1590/S1982-21702013000100007

10. Kalman, R.E., A new approach to linear filtering and prediction problems. Transactions of the ASMEJournal of Basic Engineering, 82 (D): 35-45, 1960, DOI $10.1115 / 1.3662552$

11. Kamiński W., New method for determination of adjustment corrections for crane rail axes, Reports on Geodesy vol. 94/2013, 47-55, DOI: 10.2478/rgg-2013-0006 , 2013

12. Křemen T., Koska B., Pospíšil J., Kyrinovič P.,Haličková J., \& Kopáčik A., Checking of crane rails by terrestrial laser scanning technology, 13th FIG, 4th IAG, Lnec, Lisbon 12-15 May, 2008

13. Kyrinovič P., \& Kopáčik A., Automated measurement system for crane rail geometry determination, 27th International Symposium on Automation and Robotics in Construction (ISARC 2010), 294 - 305, 2010

14. Marjetič A., Kregar K., Ambrožič T., \& Kogoj D., An Alternative Approach to Control Measurements of Crane Rails, Sensors, 12, 5906-5918, 2012, DOI 10.3390/ s120505906

15. Naus K., The effect of measurements burdened with gross error on the accuracy of ship position estimation with the aid of extended Kalman filter and robust geodesic adjustment (in Polish), Logistyka, 3/2014, 4589-4602, 2014

16. Shi. C., Zhao D., Peng J., Shen C., Identification of ship maneuvering model Using extender Kalman filters, TransNav, International Journal on Marine Navigation and Safety of Sea Transportation, Vol.3, No. 1, March 2009, DOI 10.1201/9780203869345.ch59

17. Stateczny A., Kazimierski W., A Concept of Decentralized Fusion of Maritime Radar Targets with Multisensor Kalman Filter, IEEE, Proceedings of IEEE 11-th International Radar Symposium, 16-18 June 2010, pp.1-4

18. Tomera M., Dynamic positioning system for a ship on harbour manoeuvring with different observers. experimental results. Polish Maritime Research Volume: 21 Issue: 3 Pages: 13-24 Published: SEP 2014

19. Wiśniewski Z., Compensatory calculation in geodesy (with examples) (in Polish), Wydawnictwo UWM, Olsztyn,2005
20. Wiśniewski Z., Advanced methods of geodetic observation processing with examples (in Polish), Wydawnictwo UWM w Olsztynie, Olsztyn, 2013.

\section{CONTACT WITH THE AUTHOR}

Daria FILIPIAK - KOWSZYK

\author{
FACULTY OF CIVIL AND ENVIRONMENTAL \\ ENGINEERING \\ Gdańsk University of Technology \\ 11/12 Narutowicz Street \\ 80 - 233 Gdańsk \\ POLAND
}

